\title{
Sherlock Holmes introduces critical thinking
}

\author{
Avani SABADE*
}

\begin{abstract}
Sherlock has been admired in medical and criminal investigative education for his detection abilities. What makes him such an iconic figure is his "science of deduction and analysis". Are there critical thinking traits in Sherlock Holmes' method which can be used for instruction? Can Holmes be considered an exemplar of critical thinking? The argument here is that Holmes' methods overlap with educational outcomes of critical thinking courses. A teaching activity designed to allow an exploration of the detective's abilities in an introductory class is described here.
\end{abstract}

\section{KEYWORDS}

teaching critical thinking; pedagogy; Sherlockian deductions

* M.A. in Philosophy, adjunct at FLAME University, Lavale, Maharashtra, India. E-mail: avani.sabade@gmail.com. 


\section{ELEMENTARY! HOLMES IN CLASS}

Sherlock Holmes has inspired interest in academics as to what can be learnt from his fictional, yet incredible, crime detection skills. These skills are based on the "science of deduction and analysis" according to Holmes. Logicians are quick to note that although termed as deduction, the reasoning in Doyle's stories is actually a combination of inductive and deductive reasoning (Uchii, 2006; Genot, 2017). Creativity and the successful process of such reasoning has brought the detective into the scholarship of both the teaching and learning of criminal investigation training, medical clinical diagnostics and professional training.

It is no surprise that the detective has been admired by criminal investigation educators. David Carson argues that abductive reasoning should be articulated and incorporated into the training of police officers. He argues that training based on an investigative mindset is insufficient because it only develops behavioral and interpersonal skills. The abductive reasoning of Holmes helps in investigative inference where available evidence is interpreted to formulate hypotheses. The hypotheses are then tested with the gathering of further evidence. Because this process is more scientific and successful, it must be included in police training. The teacher's emphasis on the cognitive process of abduction encourages healthy scepticism in students, which must be valued in investigative training as it contributes to higher success rates.

Conan Doyle's knowledge of medical science is reflected in his creations of Holmes and Watson. David Levine claims that recognising and reinforcing some of these medical skills helps to teach clinical reasoning as well as professional behaviour (Levine, 2012). Although, he recognises that the clinical reasoning for diagnostics requires many different skills: some of them derive from Holmes' methods of reasoning. In training novices in the specialised field of diagnostics, reference to Holmes makes it possible to bridge the gap between abstract principles of medical knowledge and the live context in which students must perform diagnoses. Particularly, the investigative nature of diagnostics parallels the process of developing hypotheses, which are then tested with questions, examination and investigation. The master detective starts with relevant information to develop hypotheses which are meticulously tested with further inquiry.

These two examples show how using Holmes' example can facilitate teaching and learning in the investigative fields of crime and medicine, with an emphasis on the process of reasoning. Holmes' expertise is located in various cognitive processes (Andre \& Gebot, 2008). Perceptual and reasoning processes distinguish him from novices. Methodologically, the process is compared to applied econometrics as a diagnostic evaluation of empirical modes of study (McAleer, 1994). The important processes that make up the methodology 
are: accommodating the available facts to construct a theory; gathering information; processing observations; and finding a hypothesis or model that adequately explains the data. All these involve reasoning skills along with empirical evidence collection in a systematic way. Similar methods are applied in econometrics to analyse data and perform diagnostics.

Philosophically, Holmes' method has been labelled as an interrogative model of scientific inquiry by Hintikka (Hintikka \& Hintikka, 1983). In developing a more engaged and active model of scientific inquiry, Hintikka compared Sherlock Holmes' "deductions" to an interrogative model of the logic of discovery as well. Hintikka shows the scientific model is not only in hypothesis verification but also in hypothesis formation. Sherlockian reasoning plays an important role in two ways: formulating hypotheses that accommodate observational facts at hand and then testing with an open mind these hypotheses against further empirical data that is gathered. Holmes' reasoning abilities as well as his dispositions contribute to this method, which can be more clearly seen in the explicit analysis of Sherlock's logic.

Sherlock has been hailed as a logician by Uchii for his eliminative inference (Uchii, 2006). His logical abilities are admired not only for their basis in knowledge but also for the character he portrays: When you have eliminated the impossible, whatever remains, however improbable, must be the truth.

Although labelled as "science of deduction and analysis", Uchii notes that it involves a great deal of probabilistic-inductive reasoning as well. This mixed form has been otherwise recognised as abduction. Uchii calls it eliminative reasoning which uses all these modes. Uchii lists the typical characteristics of a logician, such as being meticulously attentive to detail and having an awareness of the peculiar logical nature of inferences; he shows how these are both very much observable in Sherlock Holmes. Hintikka emphasises how the power of imagination rooted in available facts is important to devise hypotheses. The role of imagination is shown to be just like the scientific method of investigation. The scientific model has been shown in the method employed by Sherlock Holmes, which applies to many disciplines.

Skills taught in various curricula that can benefit from references to methods and habits of Holmes are:

1) Abduction-based interpretation of scattered facts (in criminal investigation).

2) Scientific method of testing hypotheses with facts leading to higher success.

3) Methods of formulating hypothesis accommodating currently known facts.

4) Testing hypothesis through questioning, examining, investigating.

5) Isolating relevant facts as part of taking patient history (in medicine).

6) Applying abstract principles of medical or other subject specific knowledge.

7) Perceptual and cognitive processes of an expert.

8) Loop of diagnostic evaluation of empirical study comparable to applied econometrics. 
Sherlock Holmes' logical abilities and dispositions are applied in diverse fields, and his reasoning ability is the common factor. What remains to be seen is if it qualifies as critical thinking. The following section looks for the connections between these traits of Holmes recognised as useful for instruction across various disciplines and the abilities, skills, dispositions, habits, and attitudes central to critical thinking education.

\section{IS SHERLOCK HOLMES A CRITICAL THINKER?}

The scholarship of teaching and learning about Sherlock Holmes reviewed so far is derived from investigative disciplines, which raises the question: what role can Sherlock Holmes play in teaching and learning critical thinking? Although Uchii has shown Holmes to be a logician, Holmes's traits need to be measured against the unique features of critical thinking.

Critical thinking plays an important role in education currently. As the understanding of critical thinking has changed together with the evolving systems of education, its definition and instruction strategies are refined to suit. In the critical thinking movement (Ennis, 2011), some common abilities, skills, habits, dispositions, and attitudes are part of the definitions of critical thinking and of educational goals based on them. They are listed here along with whether or not Holmes displays them.

\begin{tabular}{|c|c|c|c|}
\hline Abilities, skills & $\begin{array}{l}\text { Sherlock } \\
\text { Holmes }\end{array}$ & $\begin{array}{c}\text { Dispositions, attitudes, } \\
\text { habits }\end{array}$ & $\begin{array}{l}\text { Sherlock } \\
\text { Holmes }\end{array}$ \\
\hline Observational & Yes & Attentiveness & Yes \\
\hline Emotional & ? & Habit of inquiry & Yes \\
\hline Questioning & Yes & Self-confidence & Yes \\
\hline Imaginative & Yes & Courage & Yes \\
\hline Inferential & Yes & Open-mindedness & Yes \\
\hline Experimenting & Yes & $\begin{array}{l}\text { Willingness to suspend } \\
\text { judgment }\end{array}$ & Yes \\
\hline Consulting & Yes & Trust in reason & Yes \\
\hline Argument analysis & Yes & Seeking the truth & Yes \\
\hline Judging & Yes & & \\
\hline Deciding & Yes & & \\
\hline
\end{tabular}


The detective is famous for his observational, experimental, and imaginative approach alongside his ability to judge and his decision making abilities and skills. He is very attentive, especially to the evidence relevant to seeking the truth with confidence and courage. Anyone familiar with Sherlock Holmes knows how he has these abilities, skills, dispositions, attitudes, and habits. The only one that we cannot be certain about are his emotional abilities. Emotional abilities are broadly understood as emotional intelligence. Under critical thinking the following emotional abilities become important: curiosity, collaborative thinking, recognising one's own and others' emotional reactions, biases, and commitments. Sherlock Holmes has been popularly claimed as a "high-functioning sociopath", in the recent adaptation, so his emotional abilities are perhaps the most difficult to clearly accept or reject.

Although, in this recent adaptation, Sherlock is portrayed with a personality disorder, the original character can be understood as emotionally intelligent. Originally, Sherlock controls his emotions to disallow any bias in his reasoning ability and precise judgement. The typical markers of autistic or any other personality disorder are missing in the original Sherlock Holmes. The recent portrayal of him, in the BBC adaptation Sherlock, misses the mark of actually showing him as a sociopath, as claimed in the series, despite the emphasis on his poor behaviours. Returning, to the original characterisation, Sherlock Holmes shows intellectual and moral virtues that can complement emotions. Sherlock's focus on knowledge and reasoning leaves scope for improvement when it comes to his emotional abilities. They are not absent, but they certainly are not as mastered as his "deductive" skills. Sherlock Holmes may not display philosophical inclinations, as he is primarily concerned with solving practical problems at hand, but as can be seen the characteristics considered central to critical thinking certainly contribute to his investigative method and success.

Philosophers have compared Sherlock's reasoning abilities with logical standards of argumentation. There are clear overlaps, as well as many missing aspects, when contextualised within the philosophy of science (Eco \& Sebeok, 1983). Since deductive logic was often referred to as the method followed by Sherlock Holmes for his detective abilities, deduction is explained using examples of his reasoning. Those who recognise Sherlock Holmes as a critical thinker only use it as an example of good and successful arguments (Facione, 2015). As already shown, scholarship of teaching and learning that refers to Sherlock Holmes only uses his subject-specific skills; although, they are based on his reasoning skills. In the scholarship of teaching and learning of philosophy, particularly critical thinking, Sherlock Holmes' detective abilities that are based on sound reasoning are a missed opportunity. This paper takes this opportunity and develops it into a teaching activity for critical thinking based on him. 


\section{SHERLOCKIAN DEDUCTIONS: LET'S PLAY DETECTIVE}

A teaching activity meant to introduce critical thinking is called "Sherlockian deduction: Let's play detective”. It works as follows: students are given a prompt and instructions on how to deduce like Sherlock Holmes. The prompt can be designed to fit the approach of the course. Based on the prompt, students are expected to make "Sherlockian deductions". For example, in a blended course, the prompt can be from the subject matter being taught. Some exercises available in critical thinking books can be modified for use in a standard approach class. ${ }^{1}$

The instructions ensure that the deductions remain the domain of interest in order to keep the focus on the desired skills and traits for an introductory class. The deductions are then "explained" or justified in the second step. Here, the instructor reveals the thinking process, and the instructor puts up the "deductions" in their argumentative format. Depending on the goals of the introductory class, these arguments provide rich material for analysis and evaluation. Argument mapping of a basic form can be visually performed at this stage. Aspects of the arguments, such as skills and abilities, can be analysed based on the argument mapping. On the personal side, the dispositions, habits and attitudes of the students can be compared to the ones displayed by Holmes. Next, whether they are virtues of critical thinking can be discussed. The main advantage of this teaching activity is that a popular culture figure is used, which improves student engagement and retains academic rigour because it delivers the aims of a critical thinking course.

\section{TEACHING CRITICAL THINING: WHERE DOES THE DETECTIVE FIT IN?}

Although Holmes displays many attributes of the critical thinker, can he actually help teach critical thinking? If yes, how? How the Holmesian methods can be used for critical thinking instruction is shown through an exploration of a cross-section of pedagogies of philosophy and critical thinking. Critical thinking is termed as the educational import of rationality aimed at academic as well as personal growth and maturity (Siegel, 1989). In designing critical thinking courses, there are four approaches (Ennis, 2011). The standard approach is designed to teach argument analysis and evaluation with certain abilities, skills, dispositions, habits, and attitudes. The infused approach blends

\footnotetext{
${ }^{1}$ There are two options for the prompt: a personal one allows students to "deduce" specific traits of the instructor. This allows a display of open-mindedness from the instructor. If this is too personal, the other option is to use exercises available in critical thinking books such as Thompson, 2019; Tulpule, 2018.
} 
critical thinking into already existing courses in other subjects and makes explicit reference to the critical thinking components. The immersed approach also blends critical thinking into existing curricula but without an explicit reference to it. Mixed approaches tend to derive from both of these modes to design a course that fits the required educational purpose. Pedagogies of critical thinking are discussed in this paper with the standard approach in mind, but some pedagogies are flexible enough to be applicable to any of these approaches.

Philosophising aims to understand various arguments and formulate well-founded positions through rational argumentation and discussion (Thomas, 2019). These aims overlap with critical thinking as they deal with argumentation and its fair evaluation. Critical thinking is the educational import of fostering rationality which forms the common ground between philosophy and critical thinking (Siegel, 1989). This implies that pedagogies of philosophy and critical thinking are aligned too. So, the following discussions draw from scholarship of teaching and learning from both philosophy and critical thinking.

Teaching for intellectual virtues and step-by-step process are two pedagogies aimed at effective teaching and learning of critical thinking. Intellectual virtues should be added to the instruction of critical thinking because skills and abilities are only parts of educational goals. Dispositions, habits and attitudes of critical thinking were not sufficiently addressed originally because the focus was almost entirely on abilities and skills, this gap can be filled by focusing on teaching intellectual virtues (Byerly, 2019). Virtue epistemologists have shown that such instruction in intellectual virtues makes students better inquirers by guiding how they inquire. Holmes provides the personal icon of thinking, so analysis of whether a particular inference was based on virtue or vice of critical thinking allows hands-on training. Instruction designed in this way analyses not only thinking but also the thinker, which serves the aim of evaluation of dispositions, habits and attitudes.

Step-by-step pedagogy based in deliberate practice builds components of critical thinking in a cumulative manner (Cahill \& Bloch-Schulman, 2012). It is considered suitable because the nature of critical thinking skills is cumulative. Understanding, evaluating, and constructing arguments are cumulative skills. They cover intellectual skills as well as dispositions and the habits of mind necessary to live as a critical thinker. Step-by-step pedagogy has been developed in the standard critical thinking course, but it can work just as well in the other approaches because the cumulative skills and dispositions of critical thinking can be blended into other curricula. Sherlockian deductions can be used as the first activity in understanding and mapping arguments in this pedagogy, and then subsequent skills can be built on that basis. Arguments that students produce can also be used later as prompts for each skill, which 
can be followed up with further extensive exercises. Through this cumulative process, the arguments (Sherlockian deductions) put forth by students can serve as examples throughout the course.

Two philosophy pedagogies also apply to critical thinking: philosophy as a transformative practice and loss through win-argument. If philosophy is a practice that transforms the subject both as a thinker and as a situated subject, then it covers not only abilities and skills but also dispositions, habits, and attitudes that make up critical thinking. Argumentation pedagogy aimed at winning arguments may be important for instruction in legal training or for political campaign management but it hinders critical thinking. The Rogerian argument method aims to overcome the shortcomings of win-argument pedagogy to allow critical thinking. It promotes open-minded reasoning and exploration in arriving at the conclusion instead of simply proving one's position. Sherlockian deductions can be useful for analysing how Holmes himself is seeking the truth rather than simply proving himself right. Although his arrogance sounds like he is just proving himself, he methodically formulates many hypotheses to be genuinely tested with further evidence instead of just proving one. This open-mindedness in inquiry can be used for instruction in the exploration of an issue in order to reach a conclusion as a critical thinker.

There are different approaches and pedagogies for critical thinking instruction. "Sherlockian deductions", as a teaching activity, serve as an introductory exercise which suits many combinations of approaches and pedagogies. As it is designed using a literary iconic figure, it allows for analysis of thought and thinker. As the students make inference from a prompt provided, arguments formulated by students can be used for analysis of cumulative skills throughout the course as well. The scholarship of teaching and learning investigative disciplines shows that Holmes is already used educationally. So, Sherlockian deductions can also be used in a blended course of critical thinking, with instructions delivered that are relevant both to the discipline as well as to critical thinking.

\section{CONCLUSION}

"Sherlockian deductions: Let's play detective" is proposed as a teaching activity that provides an introduction to critical thinking. This fills the gap of scholarship of teaching and learning based on Holmes by focusing on critical thinking traits. The scholarship focuses on Holmes for instruction in disciplines close to his expertise or the structure of reasoning used by him. The activity proposed here brings these together by explicitly focusing on Holmes' abilities, skills, dispositions, habits and attitudes as a critical thinker. The activity allows students to explore these traits themselves and evaluate them too. 


\section{BIBLIOGRAPHY}

Andre, D. \& Gebot, F. (2008). Sherlock Holmes - an expert's view of expertise. British Journal of Psychology, 99, 109-125.

Byerly, R.T. (2019). Teaching for intellectual virtues in logic and critical thinking classes: why and how. Teaching Pbilosopby, 42(1), 1-27.

Cahill, A.J. \& Blach-Schulman, S. (2012). Argumentation step-by-step: learning critical thinking through deliberate practice. Teaching Philosophy, 35(1), 41-62.

Carson, D. (2009). The abduction of Sherlock Holmes. International Journal of Police Science and Management, 11(2), 193-202.

Collier, M.W. (2013). Critical thinking instruction in academia: what can the US intelligence community expect?. Journal of Strategic Security, 6(3), 61-64.

Conan Doyle, A. (2018). The complete Sherlock Holmes. Noida: Maple Press.

Davis, J.R. (2013). Socrates in homeroom: a case study for integrating philosophy across a high school curriculum. Teaching Philosophy, 36(3), 217-238.

Eco, U. \& Sebeok, Th.A. (Eds.). (1983). The sign of three: Dupin, Holmes, Peirce advances in semiotics. Bloomington: Indiana University Press.

Ennis, R.H. (2011). The nature of critical thinking: an outline of critical thinking abilities and dispositions. Presentation at Sixth International Conference on Thinking at MIT, Cambridge, MA, July, 1994. Accessed: https://education.illinois.edu/docs/default-source/faculty-documents/robert-ennis/thenatureofcriticalthinking_51711_000.pdf?sfvrsn=7bb51288_2 (12.09.2020).

Facione, P. (2015). Critical thinking: what it is and why it counts. Insight Assessment. Accessed: https://www.researchgate.net/publication/251303244_Critical_Thinking_What_It_Is_ and_Why_It_Counts (12.09.2020).

Genot, E.J. (2017). Strategies of inquiry the 'Sherlock Holmes sense of deduction' revisited. Synthese, 195, 2065-2088. Accessed: https://doi.org/10.1007/s11229-017-1319-x (12.09.2020).

Grosskopf, W.L. (2015). When win-argument pedagogy is a loss for the composition classroom. Argument: Biannual Philosophical Journal, 5(1), 243-265.

Hanuszkiewicz, W. (2019). Concept of pedagogy as applied philosophy: Paul Natorp, John Dewey and Sergius Hessen. Argument: Biannual Philosopbical Journal, 9(2), 201-223.

Hintikka, J. \& Hintikka, M.B. (1983). Sherlock Holmes confronts modern logic: Toward a theory of information-seeking through questioning (pp. 154-170). In: U. Eco \& Th.A. Sebeok (Eds.), The sign of three: Dupin, Holmes, Peirce advances in semiotics. Bloomington: Indiana University Press.

Hitchcock, D. (2018). Critical thinking. The Stanford encyclopedia of philosophy (E.N. Zalta, Ed.). Accessed: https://plato.stanford.edu/archives/fall2020/entries/critical-thinking (12.09.2020).

Kincheloe, J.L. (2000). Making critical thinking critical (pp. 23-40). In: D. Weil \& H.K. Anderson (Eds.). Perspectives in critical thinking: Essays by teachers in theory and practice. Counterpoints. New York: Peter Lang Publishing.

Levine, D. (2012). Revalidating Sherlock Holmes for a role in medical education. Clinical Medicine, 12(2), 146-149.

McAleer, M. (1994). Sherlock Holmes and the search for truth: a diagnostic tale. Journal of Economic Surveys, 8(4), 317-370.

McCuskey, B. (2012). Sherlock Holmes and intelligent design. The Quarterly Review of Bio$\log y, 87(3), 225-235$.

Saguillo, J.M. (2014). Hintikka on information and deduction. Teorema, 33(2), 75-88. 
Siegel, H. (1989). The rationality of science, critical thinking, and science education. Synthese, $80(1), 9-14$.

Thomas, P. (2019). Philosophy as transformative practice: a proposal for a new concept of philosophy that better suits philosophy education. Argument: Biannual Philosophical Journal, 9(2), 185-199.

Thomson, A. (2019). Critical reasoning: A practical introduction. New Delhi: Routledge.

Tulpule, A. (2018). Sense and syllogism: Logic in life. Chandigarh: White Falcon Publication.

Uchii, S. (2006). Sherlock Holmes and probabilistic deduction. Accessed: http://www1.kcn. ne.jp/h-uchii (12.09.2020).

Weil, D.K. (1998). The critical thinking movement (pp. 47-92). In: D. Weil \& H.K. Anderson (Eds.). Perspectives in critical thinking: Essays by teachers in theory and practice. Counterpoints. New York: Peter Lang Publishing. 